\title{
Nitrate limitation and accumulation of dissolved organic carbon during a spring-summer cyanobacterial bloom in Lake Taihu (China)
}

\author{
Linlin YE, ${ }^{1,2}$ Xiaoli SHI, ${ }^{2}$ Xiaodong WU, ${ }^{3}$ and Fanxiang KONG ${ }^{2 *}$ \\ ${ }^{1}$ School of Geography Science, Nantong University, 999 East Waihuan Road, Nantong 226019, China; ${ }^{2}$ State key Laboratory of Lake \\ Science and Environment, Nanjing Institute of Geography and Limnology, Chinese Academy of Sciences, 73 East Beijing Road, \\ Nanjing 210008, China; ${ }^{3}$ Cold and Arid Environmental and Engineering Research Institute, Chinese Academy of Sciences, 320 West \\ Donggang Road, Lanzhou 73000, China \\ *Corresponding author: fxkong@niglas.ac.cn
}

\begin{abstract}
Lake Taihu, high-molecular-weight dissolved organic matter (HMW-DOM), with sizes between $1 \mathrm{kDa}$ and 0.2 um, were collected using cross-flow ultrafiltration, from three different eutrophic regions. The DOC, and HMW-DOC concentrations, as well as environmental factors, including water temperature, nitrate, phosphate, and Chlorophyll-a (Chl-a), were analyzed. A significant negative relationship was observed between Chl-a and nitrate concentration, suggesting that cyanobacterial bloom was limited by nitrate. The high phosphate concentration can probably be attributed to phosphorus released from the sediment or can be a result of the accumulation of bloom. Furthermore, DOC concentration significantly increased with water temperature, and was negatively related to nitrate concentration, indicating that these two environmental factors are well correlated to DOC dynamics. DOC concentration did not significantly corresponded with the Chl-a concentration in Lake Taihu. Moreover, the relationship between HMW-DOC and Chl-a concentration was only observed in Gonghu Bay, suggesting that DOC and HMW-DOC are not solely derived from cyanobacterial bloom. Other organic carbon origins, such as terrestrial input, were also assumed to play an important role in Lake Taihu.
\end{abstract}

Key words: cyanobacterial bloom, dissolved organic carbon, nitrate limitation, water temperature.

Received: May 2011. Accepted: September 2011.

\section{INTRODUCTION}

Cyanobacterial blooms, which are most abundant from spring to autumn, are regularly occurring features of a large number of aquatic ecosystems in China (Xu et al. 2010). The contribution of cyanobacterial blooms to dissolved organic matter (DOM) formation and accumulation is substantial (Meon, and Kirchman 2001). The algal DOM released from Microcystis aeruginosa contributes considerably to the organic matter in Lake Biwa (Aoki et al. 2008). DOM concentration and composition may also be affected by nutrient variation, particularly nitrate. Wetz, and Wheeler (2003) observed a significant accumulation of DOM after the nitrate depletion of the phytoplankton. A shift in DOM composition from being a carbon-enriched to a nitrogen-enriched material was observed during cyanobacterial cell lysis induced by nitrate depletion after the 2009 bloom in Lake Taihu (Ye et al., in press). Thus, understanding the effects of blooms and environmental factors on carbon dynamics is important for future predictions and for the controls of affected regions in the aquatic ecosystem.

The two most important components of DOM are dissolved organic carbon (DOC) and dissolved organic nitrogen (DON). Phytoplankton blooms have a significant effect on DOC pools relative to DON (Gobler, and Sañudo-Wilhelmy 2003). The molecular composition of DOC is complicated. A large proportion of the DOC produced during phytoplankton blooms were reported to be high-molecularweight (HMW)-DOC (Gobler, and Sañudo-Wilhelmy 2003). Both bulk and HMW-DOC (>1 kDa) pools were analyzed and compared with Chlorophyll- $a$ (Chl- $a$ ) concentration to ascertain how the DOC composition is affected by the development of cyanobacterial blooms. The resulting data provide insights into DOC dynamics and sources during algal bloom. The current study is the first to extensively analyze the characteristics of DOC in relation to cyanobacterial bloom in Lake Taihu.

\section{MATERIALS AND METHODS}

Site description

Lake Taihu is one of the largest freshwater lakes in China and is located in the southeast portion of the Yangtze River Delta (latitude $30^{\circ} 55^{\prime} 40^{\prime \prime}-31^{\circ} 32^{\prime} 58^{\prime \prime} \mathrm{N}$; longitude $\left.119^{\circ} 52^{\prime} 32^{\prime \prime}-120^{\circ} 36^{\prime} 10^{\prime \prime} \mathrm{E}\right)$, with an area of $2340 \mathrm{~km}^{2}$. Cyanobacterial bloom occurs annually in late May or early June, and the large volume of cyanobacteria colonies is driven to the western and northern areas of Lake Taihu by the high frequency of southwest winds (Wu et al. 2010). In 
the present study, surface water samples from Lake Taihu were obtained monthly from March to August 2010. The sampling sites were categorized into three regions, namely, (1) Meiliang Bay, one of the most eutrophic bays in the northern section of the lake, with a high density of Microcystis scums in summer (Chen et al. 2003); (2) Lake centre, an open lake without serious water bloom in summer; and (3) Gonghu Bay, which used to be dominated by submerged macrophytes (Zhang et al. 2006) and is now less eutrophic than Meiliang Bay (Fig. 1).

In the present study, the results of microscopy determination indicated that the cyanobacteria comprised more than $95 \%$ of the phytoplankton in the three sampling sites during all sampling periods. Therefore, Chl- $a$ concentrations were used to represent the abundance of cyanobacteria.

\section{Analytical procedures}

Three replicate measurements of subsamples from each sample were performed. Chl- $a$ that was collected on a $\mathrm{GF} / \mathrm{C}$ filter and extracted with $90 \%$ acetone was measured using the method described by Yan et al. (2004). Ultrafiltration was performed using a Millpore Pellicon standard system with a $1 \mathrm{kDa}$ regenerated cellulose PLAC filter cartridge (filter area $0.5 \mathrm{~m}^{2}$ ). The water samples were filtered through $0.2 \mu \mathrm{m}$ pore size filter prior to ultrafiltration. Procedures for the ultrafiltration of collected samples are described by Guo, and Santschi (1996). HMW-DOM is defined as DOM with a molecular weight between $1 \mathrm{kDa}$ and $0.2 \mu \mathrm{m}$. DOC and HMW-DOC were analyzed through the high-temperature catalytic oxidation method using a total organic carbon analyzer (Shimadzu TOC-V CPN, Japan) (Zhang et al. 2006). After ultrafiltration, aliquots of both retentate and ultrafiltrate were sampled for a DOC

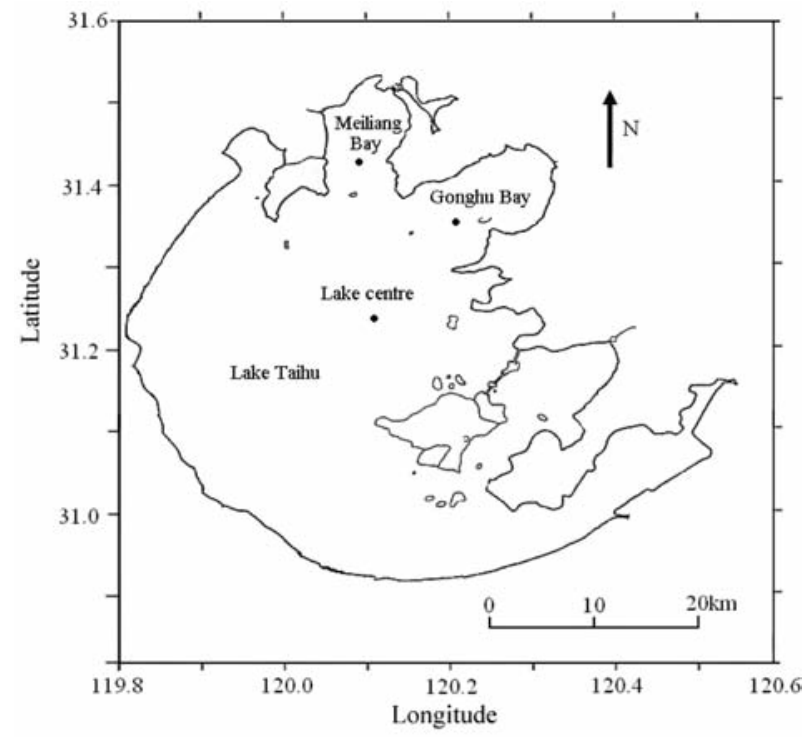

Fig. 1. Location of the sampling sites in Lake Taihu. mass balance (Guo, and Santschi 1996). Concentrations of the nitrate and phosphate were determined using a continuous flow analyzer (Skalar San plus, Netherlands).

Statistical analysis

The SPSS 16.0 software package was used for statistical analysis. Differences among means were determined using a two-tailed $t$-test. Differences were considered significant at $p<0.05$. All data were presented as mean \pm standard deviations. The relationships between Chl- $a$ and nitrate and DOC and HMW-DOC concentrations were described using linear regression.

\section{RESULTS}

Chl- $a$ primarily increased in July, whereas the Chl- $a$ values were substantially lower during the rest of the sampling period, except at the Meiliang Bay station (Fig. 2a). The differences in the Chl- $a$ concentration between Meiliang Bay and Lake centre was significant $(\mathrm{n}=6, p=0.05)$. Nitrate concentration fluctuated until April and became stable afterwards, then decreased continuously after June in all three lake regions (Fig. 2b). Phosphate concentration fluctuated from March to July, but increased noticeably in August at all three lake sites (Fig. 2c).

DOC concentration clearly increased in the three sampling sites. In Meiliang bay, the maximum DOC concentrations were observed in July. In Lake centre and Gonghu Bay, the highest DOC concentrations were observed in August (Fig. 3a). No significant differences were found in DOC concentration among the three sampling sites. In Meiliang Bay and Lake centre, the HMW-DOC concentra-
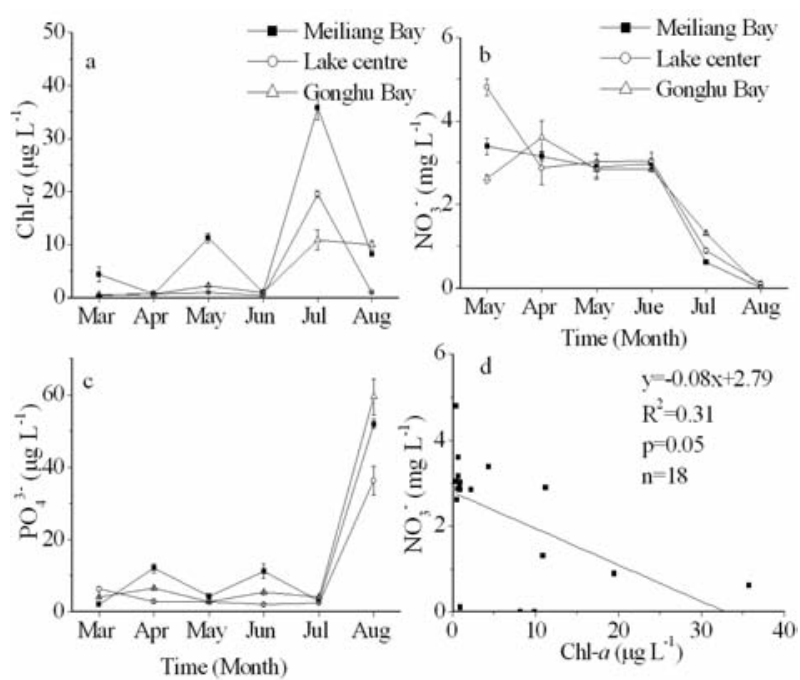

Fig. 2. Chl- $a$ (a), nitrate (b), and phosphate (c) concentrations from March to August 2010 in Lake Taihu, and the relationship between Chl- $a$ and nitrate from March to August 2010 in Lake Taihu (d). 
tion increased starting in March, reached the maximum values in June, and then fluctuated. In Gonghu Bay, HMWDOC concentration increased gradually from $1.2 \pm 0.1 \mathrm{mg}$ $\mathrm{L}^{-1}$ in March to $2.7 \pm 0.03 \mathrm{mg} \mathrm{L}^{-1}$ in August (Fig. 3b). No significant differences in HMW-DOC concentration were found among the three sampling sites. The HMW-DOC fraction of the total DOC increased from 37\% and 34\% in March to $84 \%$ and 64\% in June in Meiliang Bay and Lake centre, respectively. In Gonghu Bay, the fraction increased from 30\% in March to 51\% in August (Fig. 3c).

\section{DISCUSSION}

Relationship between Chl- $a$ and nutrients

Chl- $a$ concentration in Meiliang Bay was significantly higher than that in Lake centre from March to August. A similar Chl- $a$ spatial distribution was also found by Chen et al. (2003). The bioavailability of $\mathrm{N}$ and $\mathrm{P}$ during the growth season plays an important role in controlling bloom formation and magnitude (Nalewajiko, and Murphy 2001). The extremely high levels of cyanobacteria biomass during the summer of 2010 created substantial cellular demand for nutrients. A negative linear correlation between Chl- $a$ and nitrate concentration was observed in the present study (Fig. 2d), indicating that nitrate was depleted during the cyano-bacterial bloom, which is consistent with the findings of another study (Mei et al. 2005). Moreover, nitrate is the primary form of inorganic $\mathrm{N}$ in Lake Taihu, especially in spring. The peak of cyanobacteria biomass in Lake Taihu is associated with the maximum nitrate concentration (Mccarthy et al. 2007). Total phytoplankton biomass and growth rates increased significantly with additions of $\mathrm{N}$ in

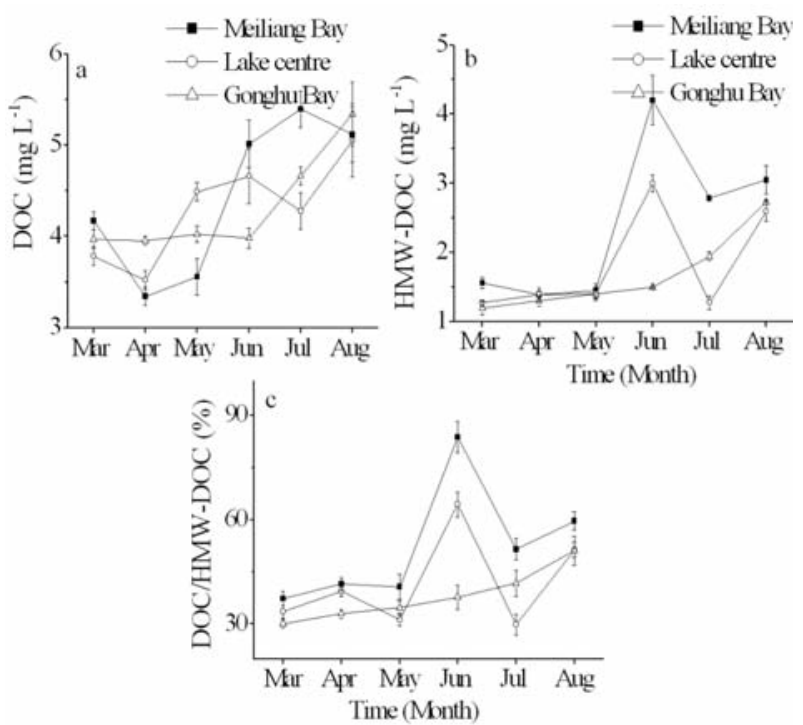

Fig. 3. DOC (a), and HMW-DOC (b) concentrations and the proportion of HMW-DOC in DOC (c) from March to August 2010 in Lake Taihu. summer and autumn, suggesting $\mathrm{N}$ limitation of phytoplankton growth in Lake Taihu (Xu et al. 2010).

A high concentration of $\mathrm{P}$ is believed to be favorable for the production of cyanobacterial bloom (Smith 1983). The high phosphate levels in the present study probably resulted from the large cyanobacteira biomass but did not facilitate the bloom because no correlation was found between concentrations of Chl- $a$ and phosphate during the spring-summer bloom (Wu et al. 2010).

The $\mathrm{P}$ forms and concentrations can be affected by numerous factors. Internal P loading is widely known as a major source of $\mathrm{P}$ in eutrophic lakes (Boström 1984). Massive $\mathrm{P}$ release from sediments may be induced by the elevated $\mathrm{pH}$ levels observed during photosynthetically active summer blooms (Xie et al. 2003), consequently resulting in the high phosphate concentration in August in the current study.

Factors associated with DOC dynamics

Water temperature showed a seasonal pattern without significant differences among Meiliang Bay, Lake centre, and Gonghu Bay. Average water temperature increased continuously from March to August. After June, the water temperature exceeded $25^{\circ} \mathrm{C}$.

Temperature is one of the most important ecological parameters affecting phytoplankton growth and biological activity. High temperature could be the factor triggering the cyanobacteria bloom (Robart, and Zohary 1987). Annual fluctuations in DOC concentration are closely associated with phytoplankton blooms (Simjouw et al. 2004). DOC concentration exhibited an increase during the spring-summer bloom in the present study, and a significant difference in DOC concentration in all the three sampling sites was found between March and August $(\mathrm{n}=3, p=0.01)$. Furthermore, these results suggest that DOC was stimulated by increased water temperature because DOC concentrations followed averaged water temperature variation (Fig. 4a).

In Lake Taihu, a cyanobacterial bloom occurs as a colonial morphology under natural conditions with a large amount of extracellular polysaccharides, the content of which significantly interacts with nitrogen concentration (Wang et al. 2011). Generally, polysaccharides are released, especially under conditions of nitrogen deficiency (Wang et al. 2010). The primary source of DOC $(60 \%)$ is known to be exudation by phytoplankton growing under nitrogen limitation (Meersche et al. 2004). In the present study, a significant inverse relationship was observed between nitrate and DOC concentration, suggesting that the accumulation of DOC can be attributed to nitrate depletion (Fig. 4b).

The correlation between DOC and Chl- $a$ concentration is complicated. A significant correlation was found between Chl- $a$ and DOC concentration during a brown-tide bloom (Simjouw et al. 2004). At a mid-Atlantic coastal bay, a dra- 

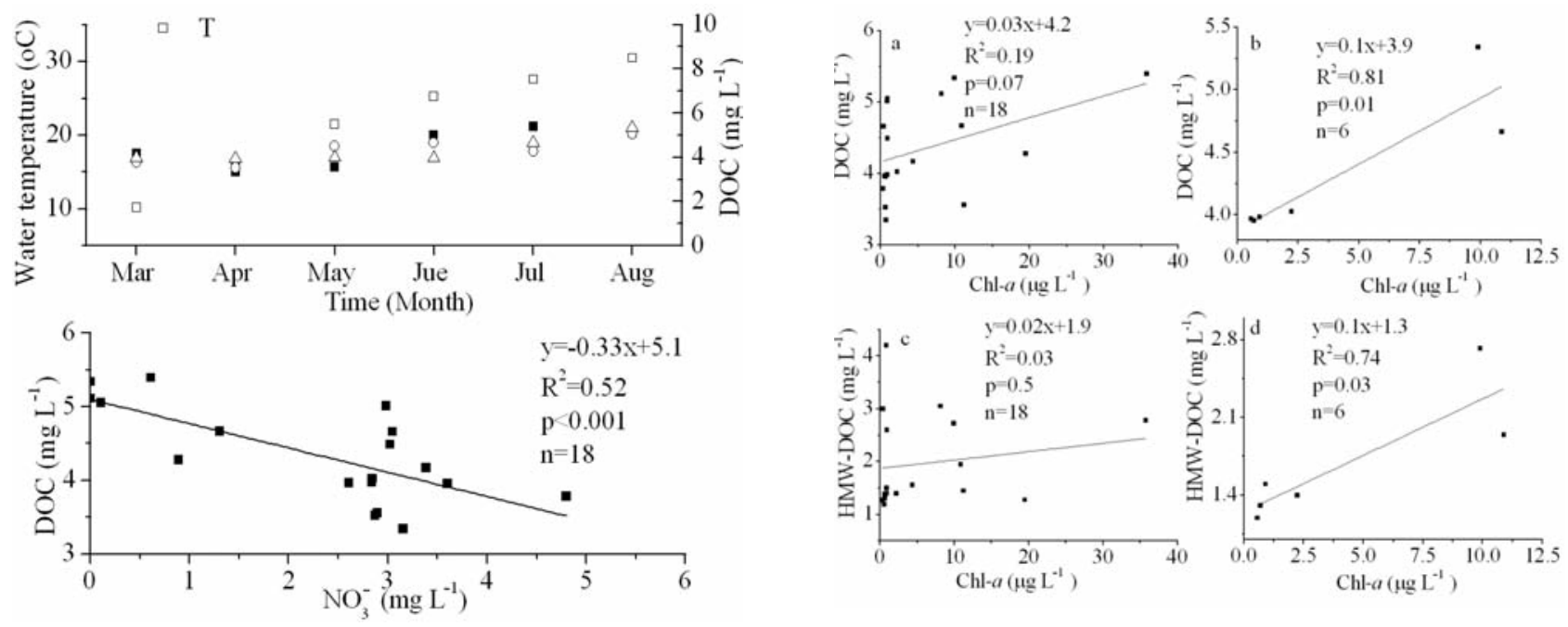

Fig. 4. The upper panel shows changes in water temperature and DOC concentration from March to August 2010 in Lake Taihu (the white hollow box ( $\square$ ) represents the average water temperature in Lake Taihu, the solid black box( $\mathbf{a})$ represents the DOC concentration in Meiliang Bay, the hollow circle ( $\mathrm{O}$ ) represents the DOC concentration in the lake center, and the hollow triangle $(\triangle)$ represents the DOC concentration in Gonghu Bay), and the lower panel shows the negative linear relationship between nitrate concentration and DOC from March to August 2010 in Lake Taihu.

matic increase in DOC concentration was observed after a brown-tide bloom, but no correlation between DOC and Chl- $a$ was reported (Minor et al. 2006). In the present study, no significant correlation between DOC concentration and Chl- $a$ was observed in the entirety of Lake Taihu (Fig. 5a), except at the Gonghu Bay station (Fig. 5b). Although phytoplankton have been reported as a potential contributor to DOC production, a large number of different biotic and abiotic processes are also involved, including grazing, photochemical oxidation, and adsorption into sinking particles (Lindell et al. 1995). In the two other sites, the exogenous sources of DOC, i.e., riverine and off-shore water, may be significantly more important in DOC dynamics. Large amounts of untreated wastewater from factories and residential areas are discharged into the Liangxi and Zhihu Gang Rivers before these rivers empty into Meiliang Bay.

\section{Variation of the HMW-DOC concentration}

Results from ultrafiltration studies show an increase in the HMW-DOC and the percentage HMW-DOC of the total DOC pool in all the three sampling sites from March through August 2010. This finding is consistent with that of a previous study that showed that the HMW-DOC fraction of the total DOC increased from the spring values of approximately $20 \%$ for the Public Landing site and 35\% for the Greenbackville site to higher values of approxi-

Fig. 5. Relationships between DOC and Chl a concentration from March to August 2010 in Lake Taihu (a) and in Gonghu Bay (b), and the relationships between HMW-DOC and Chl a concentration from March to August 2010 in Lake Taihu (c) and in Gonghu Bay (d).

mately $60 \%$ for both sites in August and September. Furthermore, HMW-DOC was reported to be strongly correlated with Chl- $a$ during an estuarine phytoplankton bloom (Gobler, and Sañudo-Wilhelmy 2003). In the current study, no significant correlation between HMW-DOC concentration and Chl- $a$ was observed in the entirety of Lake Taihu (Fig. 5c), except in Gonghu Bay (Fig. 5d), indicating that cyano-bacterial bloom is a direct source of HMW-DOC only in Gonghu Bay.

Humic substance derived from the diagenesis of structural materials from soils is an important resource for HMW-DOC in freshwater systems (Engelhaupt, and Bianchi 2001). In Lake Taihu, wind-induced resuspension of sediments occurs frequently, and thus, the materials released from sediments significantly affect the concentration of HMW-DOC in this large shallow lake (Sun et al. 2007), thereby complicating the relationship between HMW-DOC and Chl- $a$ concentrations.

\section{CONCLUSIONS}

The present study conducted an observation of DOC dynamics during the spring-summer cyanobacterial bloom in Lake Taihu. The results indicated that a cyanobacterial bloom depleted the nitrate pool, whereas DOC and HMW-DOC was enriched during the bloom. The positive correlation between HMW-DOC and Chl- $a$ in Gonghu Bay suggested that the potential source of DOC is autochthonous, possibly of cyanobacterial origin. However, DOC and HMW-DOC are not derived exclusively from cyanobacterial bloom, and other organic car- 
bon origins are also important in Lake Taihu. Future studies are required to elucidate the precise mechanism of the cyanobacterial release and bacterial assimilation in the different molecular weight DOC using ${ }^{13} \mathrm{C}$ tracer and cross-flow ultrafiltration methods.

\section{ACKNOWLEDGMENTS}

This work was financially supported by the State Key Development Program of Basic Research of China "2008CB418005" and National Natural Science Foundation of China (41001032, 40901268). We are also grateful to Daming Li, Yuanfeng Cai, and Yuhong Jia for their assistance during sample collection.

\section{REFERENCES}

Aoki S, Ohara S, Kimur K, Mizuguchi H, Fuse Y, and Yamada E. 2008. Characterization of dissolved organic matter released from Microcystis aeruginosa. Anal. Sci. 24: 389-394.

Boström B. 1984. Potential mobility of phosphorus in different types of lake sediments. Int. Rev. ges. Hydrobiol. 69: 457474.

Chen YW, Qin BQ, Teubner K, and Dokulil MT. 2003. Long-term dynamics of phytoplankton assemblages: Microcystis-domination in Lake Taihu, a large shallow lake in China. J. Plankton Res. 25: 445-453.

Engelhaupt E, and Bianchi TS. 2001. Sources and composition of high-molecular-weight dissolved organic carbon in a southern Louisiana tidal stream (Bayou Trepagnier). Limnol. Oceanogr. 46: 917-926.

Gobler GJ, and Sañudo-Wilhelmy SA. 2003. Cycling of colloidal organic carbon and nitrogen during an estuarine phytoplankton bloom. Limnol. Oceanogr. 48: 2314-2320.

Guo LD, and Santschi PH. 1996. A critical evaluation of crossflow ultrafiltration technique for sampling colloidal organic carbon in seawater. Mar. Chem. 55: 113-127.

Lindell MW, Granell, and Tranvik LJ. 1995. Enhanced bacterial growth in response to photochemical transformation of dissolved organic matter. Limnol. Oceanogr. 40: 195-199.

Mccarthy MJ, Lavrentyev PJ, Yang LY, Zhang L, Chen YW, Qin BQ, and Gardner WS. 2007. Nitrogen dynamics and microbial food web structure during a summer cyanobacterial bloom in a subtropical, shallow, well-mixed, eutrophic lake (Lake Taihu, China). Hydrobiologia 581: 195-207.

Mei ZP, Legendre L, Trembla JÉ, Miller LA, Gratton Y, Lovejoy C, Yager PL, and Gosselin M. 2005. Carbon to nitrogen (C:N) stoichiometry of the spring-summer phytoplankton bloom in the North Water Polynya (NOW). Deep Sea Res. 52: 23012304.

Meon B, and Kirchman DL. 2001. Dynamics and molecular composition of dissolved organic matter during experimental phytoplankton blooms. Mar. Chem. 75: 185-199.

Minor EC, Simjouw JP, and Mulhooland MR. 2006. Seasonal variations in dissolved organic carbon concentrations and characteristics in a shallow coastal bay. Mar. Chem. 101: 166179.

Nalewajko C, and Murphy TP. 2001. Effects of temperature, and availability of nitrogen and phosphorus on the abundance of
Anabaena and Microcystis in Lake Biwa, Japan: an experimental approach. Limnology 2: 45-48.

Robarts RS, and Zohary T. 1987. Temperature effects on photosynthetic capacity, respiration and growth rates of bloomforming cyanobacteria. New Zealand J. Mar. Freshwater Res. 21: 391-399.

Simjouw JP, Mulhilland MR, and Minor EC. 2004. Changes in dissolved organic matter characteristics in Chincoteague Bay during a bloom of the Pelagophyte Aureococcus anophagefferens. Estuaries 27: 986-998.

Smith VH. 1983. Low nitrogen to phosphorus ratios favor dominance by blue-green algae in lake phytoplankton. Science 221: 669-671.

Sun XJ, Qin BQ, Zhu GW, and Zhang ZP. 2007. Effect of windinduced wave on concentration of colloidal nutrient and phytoplantkon in Lake Taihu. J. Environ. Sci. 28: 506-511 (in Chinese with English abstract).

Van den Meersche M, Middelburg JJ, Soetaert K, Van Rijswijk P, H.T.S. Boschker, and C.H.R. Heip. 2004. Carbon-nitrogen coupling and algal-bacterial interactions during an experimental bloom: Modeling a ${ }^{13} \mathrm{C}$ tracer experiment. Limnol. Oceanogr. 49: 862-878.

Wang W, Liu Y, Geng L, Yang Z, and Chen Y. 2011. The effect of nitrogen concentration and its interaction with light intensity on population dynamics and polysaccharide content of $\mathrm{Mi}$ crocystis aeruginosa. J. Fresh. Ecol. 26: 241-248.

Wang W, Ying L, and Yang Z. 2010. Combined effects of nitrogen content in media and Ochromonas sp. grazing on colony formation of cultured Microycsits aerugionosa. J. Limnol. 69: 193-198.

Wetz MS, and Wheeler PA. 2003. Production and partitioning of organic matter during simulated phytoplankton blooms. Limnol. Oceanogr. 48: 1808-1817.

Wu XD, Kong FX, Chen YW, Qian X, Zhang L, Yu Y, Zhang M, and Xing P. 2010. Horizontal distribution and transport processes of bloom-forming Microcystis in a large shallow lake (Taihu, China). Limnologica 40: 8-15.

Xie LQ, Xie P, Li SX, Tang HJ, and Liu H. 2003. The low TN: TP ratio, a cause or a result of Microcystis blooms? Water Res. 37: 2073-2080.

Xu H, Paerl HW, Qin BQ, Zhu GW, and Gao G. 2010. Nitrogen and phosphorus inputs control phytoplankton growth in eutrophic Lake Taihu, China. Limnol. Oceanogr. 55: 420-432.

Yan R, Kong FX, and Han XB. 2004. Analysis of the recruitment of the winter survival algae on the sediment of Lake Taihu by fluorometry. J. Lake. Sci. 16: 163-168 (in Chinese with English abstract).

Ye LL, Shi XL, Wu XD, Zhang M, Yu Y, Li DM, and Kong FX. 2011. Dynamics of dissolved organic carbon after a cyanobacterial bloom in hypereutriphic Lake Taihu (China). Limnolgica: (in press).

Zhang ZP, Sun XJ, Lou ZH, Chi QQ, and Zhu GW. 2006. Analysis of colloidal organic carbon content and its influencing factors in the waters of Taihu Lake in spring. Chin. Environ. Sci. 26: 166-170 (in Chinese with English abstract). 